\title{
PERSPECTIVAS COMERCIALES DEL ECUADOR CON LOS PAIISES DE EUROPA DEL ESTE: BULGARIA, ESLOVAQUIA, HUNGRÍA, POLONIA, REPÚBLICA CHECA Y RUMANÍA, MIEMBROS DE LA UNIÓN EUROPEA
}

\author{
Halina Lyko Marczak' \\ Aníbal Robayo Lemarié2 \\ María Belén Wong 3
}

\section{RESUMEN}

El presente artículo pretende establecer las perspectivas comerciales del Ecuador con los países de Europa del Este: Bulgaria, Eslovaquia, Hungría, Polonia, República Checa y Rumanía, miembros de la Unión Europea; en función del análisis previo de la estructura del comercio exterior del Ecuador y de los citados países en el periodo 2007-2014, investigación en la que participó activamente la Ing. María Belén Wong Flores en su Tra- bajo de Titulación de la Facultad de Ciencias Administrativas y Contables de la Pontificia Universidad Católica del Ecuador.

Este Trabajo de Titulación, a su vez, fue parte de la Investigación intitulada: "Fomento de las exportaciones ecuatorianas de productos de emprendimientos populares y solidarios hacia países de Europa del Este, integrantes de la Unión Europea", el proyecto de investigación que fue financiado por la PUCE -Convo-

\footnotetext{
1 Pontificia Universidad Católica del Ecuador, Facultad de Ciencias Administrativas y Contables, Quito, Ecuador (HLYKOM@puce.edu.ec).

2 Pontificia Universidad Católica del Ecuador, Facultad de Ciencias Administrativas y Contables, Quito, Ecuador (NAROBAYO@puce.edu.ec).

${ }^{3}$ Pontificia Universidad Católica del Ecuador, Facultad de Ciencias Administrativas y Contables, Quito, Ecuador (MABELENWONG@hotmail.com).
} 
catoria 2015- y fue realizado por un equipo de los Investigadores de la PUCE, bajo la Dirección de la Master Halina Lyko Marczak.

La metodología aplicada en este trabajo es de tipo cuantitativo y cualitativo. Se incluyeron tanto fuentes primarias como secundarias, y técnicas como la observación, entrevista, análisis de los indicadores económicos publicados por el Banco Central del Ecuador en el periodo 2007-2014; Acuerdos Comerciales del periodo analizado; asimismo, se revisó publicaciones, artículos y revistas relacionadas. Además, se recopiló y se analizó la normativa oficial aplicable y vigente en el periodo, emitida por los Ministerios de Comercio Exterior, Relaciones Exteriores y Movilidad Humana, entre otras instituciones.

En cuanto a los resultados obtenidos, se demostró que la economía ecuatoriana es complementaria con cada una de las economías de estos países de Europa del Este, y que todavía el volumen del comercio exterior entre el Ecuadory los países mencionados, es realmente incipiente, por lo que se determinó que existen enormes perspectivas de mejoramiento y diversificación del intercambio comercial entre el Ecuador y los citados países.

Palabras clave: Ecuador, Unión Europea, Europa de Este, Intercambio Comercial,
Perspectivas de Comercio Exterior, Diversificación de Mercados, Complementariedad.

\section{ABSTRACT}

This article aims to establish Ecuador's trade perspectives with Eastern Europe countries: Bulgaria, Slovakia, Hungary, Poland, Czech Republic and Romania, members of the European Union; based on the preliminary analysis of Ecuador's foreign trade structure and those countries during the 2007-2014 period; the analysis was done by María Belén Wong Flores (Eng.) in her degree work for the School of Accounting and Administrative Sciences at Catholic University of Ecuador.

This work was part of the research entitled: "Promotion of Ecuadorian exports of popular and solidary enterprises to Eastern Europe countries, members of the European Union." The research project was financed by Catholic University, and was conducted by a team of researchers from this institution, under the direction of Master Halina Lyko Marczak.

The methodology used in this study is quantitative and qualitative, both primary and secondary sources were used such as: observation, interview, analysis of economic indicators published by the Central Bank of Ecuador during the 2007-2014 period; trade agreements of 
the reviewed period; besides, publications, articles and related magazines were revised. In addition, the current and applicable official regulations of the period, issued by the Foreign Trade, Foreign Affairs and Human Mobility Ministry, among others were analyzed.

The results obtained showed that the Ecuadorian economy is complementary to each of the economies of these countries in Eastern Europe, and that foreign trade volume between Ecuador and those countries is emerging, these findings determined that there are huge perspectives to improve and diversify trade.

Key words: Ecuador, European Union, Eastern Europe, Commercial Exchange, Foreign Trade Perspectives, Market Diversification, Complementarity

\section{INTRODUCCIÓN}

Para alcanzar el objetivo de establecer las perspectivas comerciales del Ecuador con los países de Europa del Este: Bulgaria, Eslovaquia, Hungría, Polonia, República Checa y Rumanía, miembros de la Unión Europea, se analizó el entorno económico nacional e internacional, lo que permitió identificar las opciones y, asimismo, proyectar la potencial expansión y buen posicionamiento de las exportaciones ecuatorianas en el mercado internacional, especialmente en los países de Europa del Este, miembros de la Unión Europea; como también permitió la generación de las propuestas de emprendimiento e investigación para mejorar y/o ampliar acuerdos comerciales que respondan a los actuales desafíos de eficiencia, globalización, innovación y responsabilidad social.

Si bien el Ecuador exporta muchos productos no petroleros como el ba- nano, café, cacao, piña, maracuyá, brócoli, flores, camarones, ciertos productos industrializados, entre otros; estos rubros en su conjunto no tienen el mismo peso que el petróleo.

El Ecuador ha concentrado en buena parte sus exportaciones de productos no petroleros en mercados correspondientes a América y Europa Occidental; lo mismo ha sucedido a nivel de sus importaciones; es decir, de los mercados y proveedores que los llamaríamos tradicionales.

Se debe señalar que hay un potencial mercado en los países emergentes de Europa del Este que tenían, después de la II guerra mundial y por aproximadamente cinco décadas, una economía, que fue relativamente restringida al comercio exterior. Estos países, en la última década, se han abierto mucho al inter- 
cambio comercial; sin embargo, el Ecuador tiene muy pocas relaciones comerciales y diplomáticas con dichos países, y eso se evidencia en que los mismos ni siquiera tienen Embajadas en el Ecuador y solamente cuentan con consulados honoríficos.

Varios de los países considerados en el presente análisis formaron parte del bloque socialista liderado por la URSS (Unión de Repúblicas Socialistas Soviéticas). Este bloque se constituyó al finalizar la Segunda Guerra Mundial, y su disolución fue a raíz de la caída del Muro del Berlín en noviembre de 1989. Característica principal de estos países consiste en que sus economías fueron centralmente planificadas, tenían comercio exterior muy restringido hacia los países capitalistas; se puede decir que no existía libre mercado.

Actualmente, sus economías se orientan hacia el libre mercado ya que son de perspectiva capitalista. Estos seis países forman parte de la OTAN y de la Unión Europea.

A continuación, se muestra algunas breves referencias productivas y comerciales de los mismos:

Bulgaria es miembro de la Unión Europea desde el primero de enero de 2007. La economía búlgara es un mercado abierto al sector privado y se carac- teriza por una estabilidad política y económica. Bulgaria es reconocida a nivel mundial por la excelente calidad de derivados lácteos como el yogur, así como de productos elaborados con aceite de rosa, vinos y licores.

Hungría es un país que pudo afrontar la caída del bloque mejor que el resto de los países que tenían sistema político-económico comunista en Europa del Este. Forma parte de la Unión Europea desde el año 2004. Las exportaciones de este país se centran en tecnología como telecomunicaciones, productos eléctricos y partes de vehículos. Las importaciones de este país son gas natural en estado gaseoso y circuitos integrados.

Polonia ingresa a formar parte de la Unión Europea en el 2004. Las importaciones principales de Polonia son el trigo, granos, aceite vegetal y alimentos de proteína, y las exportaciones en su mayoría son dulces, frutas manufacturadas, verduras y productos lácteos.

En cuanto a la ex Checoslovaquia debemos señalar que el 1 de enero de 1993 se dividió en 2 países: República Checa y Eslovaquia.

República Checa es miembro de la Unión Europea desde el 2004. Su principal mercado es Alemania, sus exportaciones en su mayoría son productos 
industriales, unidades de procesamiento y automóviles y el rubro de importación más importante es el aceite de crudo de petróleo y de mineral bituminoso.

Eslovaquia se integra a la Unión Europea en el 2004 y adopta al euro como su moneda en el año 2009. La principal industria es la automotriz, por lo que su economía se basa en la producción de automóviles y de sus componentes, los que representan un tercio de sus exportaciones. El rubro de importaciones principalmente consiste en las máquinas, aparatos y material eléctrico, sus partes y aparatos de grabación.

A partir del 2007, Rumanía forma parte de la Unión Europea. Es un país que se dedica a la producción y exportación de productos agrícolas, especialmente a los mercados de Alemania e Italia. Importa fundamentalmente aceites crudos de petróleo o de mineral, como también el gas natural en estado gaseoso.

Considerando que los seis países de Europa del Este son miembros de la Unión Europea, creemos necesario hacer una vinculación con el SGP y sus proyecciones hasta en la actualidad, a fin de relievar las derivaciones de este beneficio que es vinculante para todo el bloque y que por muchos años ha sido aprovechado por el Ecuador para el ingreso de gran cantidad de productos a
Europa en condiciones de mayor competitividad; situación que ha determinado que la UE se convierta en el segundo socio comercial del Ecuador y en el primero en cuanto a la demanda de productos no petroleros.

\section{Sistema Generalizado de Preferen- cias de la Unión Europea}

El Ecuador fue beneficiario del Sistema Generalizado de Preferencias Arancelarias (Plus) con la Unión Europea desde el año 2005, y a partir de esta fecha el país ha registrado un incremento importante de sus relaciones comerciales con este bloque. La Unión Europea otorga preferencias arancelarias en el marco del Sistema Generalizado de Preferencias (SGP Plus) a los países en vías de desarrollo. Debido a que el Ecuador fue calificado como país de renta media alta por el Banco Mundial durante, 3 años consecutivos dejó de ser beneficiario del SGP-Plus a partir del 2015; sin embargo, el 18 de diciembre del 2014 el Parlamento y el Consejo de la Unión Europea emitieron el Reglamento 1384/ 2014, a través del cual la UE se compromete a mantener las preferencias arancelarias hasta el 31 de diciembre de 2016.

\section{Acuerdo Comercial entre Ecuador y Unión Europea}

Debemos destacar que el Ecuador negoció con la Unión Europea un 
Acuerdo Comercial que permitirá la liberalización paulatina del comercio bilateral conforme a las condiciones establecidas. La negociación de este Acuerdo concluyó el 17 de julio de 2014, pero es necesario atravesar un proceso interno en la Unión Europea para la aprobación del mismo. Este proceso requerirá también, a su debido tiempo, el análisis y aprobación de los textos negociados, tanto por parte del Parlamento Europeo como de la Asamblea Nacional del Ecuador. Solo una vez que se cuente con su aprobación, el Acuerdo podrá entrar en vigencia.
Los países Bulgaria, Eslovaquia, Hungría, Polonia, República Checa y Rumanía por ser miembros de la Unión Europea se rigen bajo las leyes y normas del comercio exterior establecidas dentro del bloque de la Unión Europea, por lo que al firmar el Acuerdo Comercial entre Ecuador y Unión Europea, en el futuro también se nos abrirán mayores posibilidades de dinamizar el comercio exterior con estos países de Europa del Este que son tan atractivos para nosotros dentro de la perspectiva de diversificación de mercados.

\section{MARCO TEÓRICO}

El sustento teórico de nuestra investigación es bastante amplio; sin embargo, queremos mencionar algunas teorías que fueron referentes para el presente trabajo:

- Teoría Mercantilista: destaca la importancia de la intervención del gobierno quien promueve las exportaciones y/o restringe o limita las importaciones con el fin de mantener siempre una balanza comercial positiva.

\section{- Teoría de Ventaja Absoluta de} Adam Smith: propone la liberalización del comercio exterior y determinó que al producir un bien de manera más eficiente que otro país se lo debe exportar, mientras que el bien que se produce de manera menos eficiente se lo debe importar.

\section{- Teoría de Ventaja Comparativa de David Ricardo: establece que} el país que tiene desventaja absoluta en sus 2 bienes, debe especializarse en la producción del bien en el que tiene menor desventaja absoluta ya que en ese tendrá ventaja comparativa; en consecuencia, deberá exportar el bien en el que tiene ventaja comparativa e importar el bien en el que tiene desventaja comparativa o que se produce con mayor desventaja absoluta. 
- Teoría Heckscher-Ohlin: establece que el país debe exportar el bien que para producirse utiliza en forma intensiva los factores de producción que en ese país son abundantes, por lo cual son baratos. Mientras que se debe importar el bien que para producirse se utiliza de forma intensiva los factores de producción que en ese país son escasos, por lo que son caros.

\section{- Teoría de la Dependencia de} Prebisch: exhorta a los países en vías de desarrollo a implementar políticas que permitan generar productos con mayor valor agregado, a sustituir paulatinamente importaciones y, asimismo, aplicar estrategias o medidas de protección como aranceles y cuotas que permitan amparar la producción nacional.

\section{METODOLOGÍA}

En la presente investigación se utilizó, en primera instancia, el estudio exploratorio con el fin de conocer más sobre el tema y contar con una visión general sobre la situación del comercio exterior y las relaciones comerciales entre Ecuador y los países de Europa del Este en el periodo de estudio.

Una vez obtenido el conocimiento general, se utilizó el estudio descriptivo para comprobar e identificar la asociación entre las variables que intervienen en el estudio como tipo de producto, precio, calidad, volumen, destinatario para así determinar su incidencia en las importaciones y exportaciones ecuatorianas. Este análisis permitió determinar las perspectivas del comercio exterior ecuatoriano y acuerdos comerciales con los mercados de Bulgaria, Eslovaquia, Hungría, Polonia, República Checa y Rumanía.
En el desarrollo de la presente investigación se utilizó la fuente primaria de obtención de la información, que es la Entrevista, la cual fue aplicada a los funcionarios públicos que trabajan en los Ministerios de Comercio Exterior, Relaciones Exteriores y Movilidad Humana.

Fue necesario también recurrir a otro tipo de fuentes que son de fácil acceso y proporcionan información que se constituye en el punto de partida para el desarrollo de la investigación. Estas fuentes fueron:

- Resoluciones aplicables emitidas por el Ministerio de Comercio Exterior.

- Acuerdos comerciales entre Ecuador y los países de Europa del Este.

- Boletines emitidos por el Banco Central del Ecuador.

- Libros, revistas periódicos, enciclo- 
pedias, estudios anteriores y trabajos de titulación que proporcionen información que aporte o contribuya al tema de estudio.

- Estadísticas obtenidas de "Trade
Map" (Centro de Comercio Internacional).

- Estadísticas del Banco Mundial y Estadísticas e información de la legislación de la Unión Europea.

\section{ANÁLISIS DE RESULTADOS}

A continuación, se muestran los principales resultados de nuestra investigación:

\section{Balanza comercial bilateral Ecuador-Bulgaria}

\section{Tabla n. ${ }^{\circ}$ 1. Balanza Comercial Ecuador-Bulgaria (en miles de dólares americanos)}

\begin{tabular}{|lrrrrrrrrrr|}
\hline Descripción & 2007 & 2008 & 2009 & 2010 & 2011 & 2012 & 2013 & 2014 & $\begin{array}{c}\text { Acumulado } \\
\mathbf{2 0 0 7 - 2 0 1 4}\end{array}$ \\
\hline Exportaciones & 2941 & 2188 & 4073 & 5346 & 3589 & 11236 & 10021 & 12994 & 52388 \\
\hline Importaciones & 478 & 792 & 468 & 1221 & 10640 & 1449 & 2797 & 2977 & 20822 \\
\hline $\begin{array}{l}\text { Balanza } \\
\text { Comercial }\end{array}$ & 2463 & 1396 & 3605 & 4125 & -7051 & 9787 & 7224 & 10017 & 31566 \\
\hline
\end{tabular}

Fuente: Trade Map.

Elaboración: Halina Lyko/Aníbal Robayo/María Belén Wong

De los ocho años analizados, siete presentaron un superávit para Ecuador y solamente en el año 2011 el saldo comercial para Ecuador fue negativo. Cabe señalar que el comportamiento de la balanza comercial a lo largo de los ocho años de análisis fue irregular. Ecuador por concepto de exportaciones totalizó 52 millones 388 mil dólares, mientras que sus importaciones alcanzaron 20 millones 822 mil dólares, por lo que el saldo comercial con Bulgaria para Ecuador fue positivo y sumó 31 millones 566 mil dólares de superávit. 


\section{Balanza comercial bilateral Ecuador-Eslovaquia}

Tabla n. ${ }^{\circ} 2$. Balanza Comercial Ecuador-Eslovaquia (en miles de dólares americanos)

\begin{tabular}{|lrrrrrrrrr|}
\hline Descripción & 2007 & 2008 & 2009 & 2010 & 2011 & 2012 & 2013 & 2014 & $\begin{array}{r}\text { Acumulado } \\
\text { 2007-2014 }\end{array}$ \\
\hline Exportaciones & 3341 & 181 & 296 & 2233 & 3535 & 3329 & 678 & 106 & 13699 \\
\hline $\begin{array}{l}\text { Importaciones } \\
172\end{array}$ & 754 & 178 & 980 & 5049 & 568 & 3263 & 3459 & 14423 \\
\hline $\begin{array}{l}\text { Balanza } \\
\text { Comercial }\end{array}$ & 3169 & -573 & 118 & 1253 & -1514 & 2761 & -2585 & -3353 & -724 \\
\hline
\end{tabular}

Fuente: Trade Map.-

Elaboración: Halina Lyko/Aníbal Robayo/María Belén Wong

Los saldos comerciales para Ecuador en los cuatro años fueron negativos y en otros cuatro años positivos. El 2014 fue el año con mayor déficit comercial para Ecuador alcanzando 3 millones 353 mil dólares de déficit, mientras que el año 2007 fue el año que registró una balanza comercial positiva, más alta, para Ecuador con 3 millones 169 mil dólares.
Ecuador por concepto de exportaciones a Eslovaquia totalizó 13 millones 699 mil dólares, mientras que sus importaciones alcanzaron 14 millones 423 mil dólares, por lo que el saldo comercial con Eslovaquia para Ecuador fue negativo y sumó 724 mil dólares EE.UU de déficit.

\section{Balanza comercial bilateral Ecuador-Hungría}

\section{Tabla n. ${ }^{\circ}$ 3. Balanza Comercial Ecuador-Hungría}

(en miles de dólares americanos)

\begin{tabular}{|lrrrrrrrrr|}
\hline Descripción & 2007 & 2008 & 2009 & 2010 & 2011 & 2012 & 2013 & 2014 & $\begin{array}{r}\text { Acumulado } \\
\mathbf{2 0 0 7 - 2 0 1 4}\end{array}$ \\
\hline Exportaciones & 47 & 110 & 66 & 145 & 372 & 391 & 765 & 882 & 2778 \\
\hline $\begin{array}{l}\text { Importaciones } \\
\text { Balanza } \\
\text { Comercial }\end{array}$ & -1059 & 369 & 747 & 1193 & 6534 & 2827 & 7193 & 14008 & 33930 \\
\hline
\end{tabular}

Fuente: Trade Map.

Elaboración: Halina Lyko/Aníbal Robayo/María Belén Wong. 
Conforme podemos apreciar, los saldos comerciales en todos los años analizados fueron negativos para Ecuador. El 2008 fue el año con menor déficit comercial alcanzando solo 259 mil dólares, mientras que el año 2011 fue el año que registró el mayor déficit con 13 millones 126 mil dólares. A partir del año 2008 el saldo comercial fue cada año más deficitario para Ecuador, exceptuando el 2012 que evidenció una mejora.

\section{Balanza comercial bilateral Ecuador-Polonia}

\section{Tabla n. ${ }^{\circ}$ 4. Balanza Comercial Ecuador-Polonia} (en miles de dólares americanos)

\begin{tabular}{|lrrrrrrrrrr|}
\hline Descripción & 2007 & 2008 & 2009 & 2010 & 2011 & 2012 & 2013 & 2014 & $\begin{array}{c}\text { Acumulado } \\
\text { 2007-2014 }\end{array}$ \\
\hline Exportaciones & 24174 & 36394 & 41041 & 58178 & 56612 & 70990 & 90964 & 68556 & 446909 \\
\hline $\begin{array}{l}\text { Importaciones } \\
60082\end{array}$ & 7911 & 4195 & 11276 & 13382 & 12785 & 14631 & 15556 & 85818 \\
\hline $\begin{array}{l}\text { Balanza } \\
\text { Comercial }\end{array}$ & 18092 & 28483 & 36846 & 46902 & 43230 & 58205 & 76333 & 53000 & 361091 \\
\hline
\end{tabular}

Fuente: Trade Map

Elaboración: Halina Lyko/Aníbal Robayo/María Belén Wong

En los años analizados, los saldos de la balanza fueron positivos para Ecuador. El 2007 fue el año con menor superávit alcanzando 18 millones 92 mil dólares, mientras que el año 2013 fue el mejor año ya que evidenció un saldo comercial positivo de 76 millones 333 mil dólares.
Ecuador por concepto de exportaciones a Hungría totalizó 2 millones 778 mil dólares, mientras que sus importaciones alcanzaron 33 millones 930 mil dólares, por lo que el saldo comercial con Hungría para Ecuador fue negativo y sumó 31 millones 152 mil dólares de déficit. 


\section{Balanza comercial bilateral Ecuador-República Checa}

\section{Tabla n. ${ }^{\circ}$ 5. Balanza Comercial Ecuador-República Checa}

(en miles de dólares americanos)

\begin{tabular}{|lrrrrrrrrr|}
\hline Descripción & 2007 & 2008 & 2009 & 2010 & 2011 & 2012 & 2013 & 2014 & $\begin{array}{r}\text { Acumulado } \\
\text { 2007-2014 }\end{array}$ \\
\hline Exportaciones & 575 & 446 & 702 & 539 & 881 & 2182 & 2546 & 5181 & 13052 \\
\hline Importaciones & 3757 & 4460 & 1679 & 3873 & 16266 & 3716 & 20584 & 17306 & 71641 \\
\hline $\begin{array}{l}\text { Balanza } \\
\text { Comercial }\end{array}$ & -3182 & -4014 & -977 & -3334 & -15385 & -1534 & -18038 & -12125 & -58589 \\
\hline
\end{tabular}

Fuente: Trade Map

Elaboración: Halina Lyko/Aníbal Robayo/María Belén Wong

Del cuadro precedente se deriva que los saldos comerciales en todos los años analizados fueron negativos para Ecuador. En el año 2009, el déficit comercial fue menor alcanzando 977 mil dólares y el 2013 fue el año que registró el déficit mayor con 18 millones 38 mil dólares. El comportamiento de la balanza comercial entre Ecuador y Republica Checa presentó importantes irregularidades, ha sido fluctuante y no ha tenido un comportamiento estable.
Ecuador por concepto de exportaciones a República Checa totalizó 13 millones 52 mil dólares, mientras que sus importaciones alcanzaron 71 millones 641 mil dólares, por lo que el saldo comercial con Republica Checa para Ecuador fue muy negativo y sumó 58 millones 589 mil dólares de déficit. 


\section{Balanza comercial bilateral Ecuador-Rumanía}

Tabla n. ${ }^{\circ}$ 6. Balanza Comercial Ecuador-Rumanía

(en miles de dólares americanos)

\begin{tabular}{|lrrrrrrrrrr|}
\hline Descripción & 2007 & 2008 & 2009 & 2010 & 2011 & 2012 & 2013 & 2014 & $\begin{array}{r}\text { Acumulado } \\
\mathbf{2 0 0 7}-2014\end{array}$ \\
\hline Exportaciones & 482 & 2682 & 8393 & 10702 & 2392 & 3221 & 3622 & 5566 & 37060 \\
\hline Importaciones & 866 & 1134 & 10371 & 20249 & 11821 & 27642 & 35551 & 67736 & 175370 \\
\hline $\begin{array}{l}\text { Balanza } \\
\text { Comercial }\end{array}$ & -384 & 1548 & -1978 & -9547 & -9429 & -24421 & -31929 & -62170 & -138310 \\
\hline
\end{tabular}

Fuente: Trade Map

Elaboración: Halina Lyko/Aníbal Robayo/María Belén Wong

En el período analizado, los saldos de la balanza comercial entre Ecuadory Rumanía fueron negativos exceptuando el año 2008 que experimentó un superávit de 1 millón 548 mil dólares. El año 2007, fue el año con menor déficit alcanzando 384 mil dólares de déficit, mientras que el año 2014 fue el peor año en cuanto al saldo de la balanza comercial bilateral para Ecuador, ya que en este año se totalizaron 62 millones 170 mil dólares de déficit.

Ecuador por concepto de exportaciones a Rumanía totalizó 37,060 mil dó- lares EE.UU., mientras que sus importaciones alcanzaron 175,370 miles de dólares EE.UU, por lo que el saldo comercial con Rumanía para Ecuador fue muy negativo y sumó 138,310 mil dólares EE.UU. de déficit.

A continuación, se resalta el comportamiento y la proyección para los siguientes tres años (2015, 2016 y 2017) de los productos más importantes de las exportaciones ecuatorianas hacia cada uno de estos 6 países de Europa del Este, miembros de la Unión Europea. 


\section{Proyecciones de las exportaciones ecuatorianas hacia Bulgaria}

\begin{tabular}{|l|c|c|c|c|}
\hline \multirow{2}{*}{ Producto 1 } & \multirow{2}{*}{ Capítulo } & \multicolumn{3}{|c|}{ Proyección (miles de USD) } \\
\cline { 3 - 5 } & $\mathrm{Y} \mathrm{(2015)}$ & $\mathrm{Y}$ (2016) & $\mathrm{Y}$ (2017) \\
\hline $\begin{array}{l}\text { Frutos comestibles, cortezas } \\
\text { de agrios o de melones }\end{array}$ & 08 & 12009 & 13420 & 14832 \\
\hline
\end{tabular}

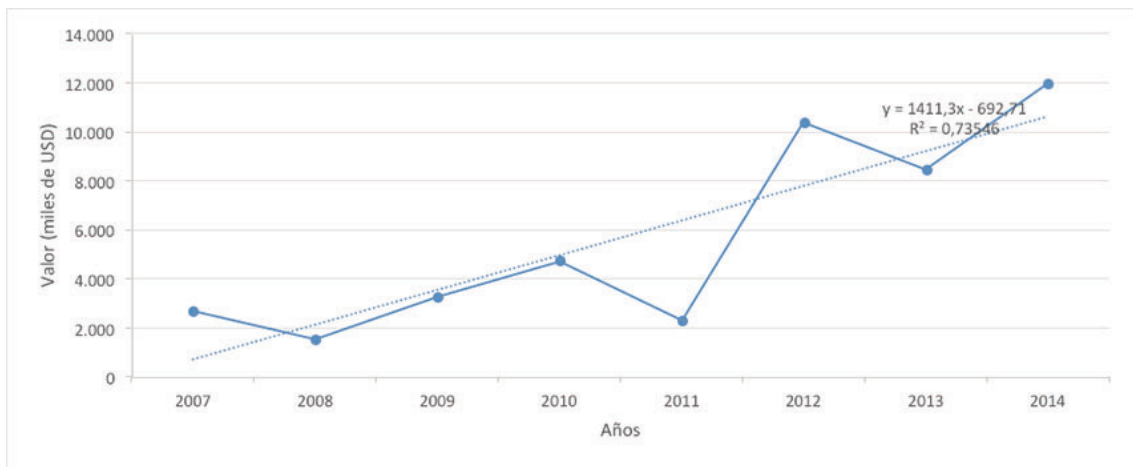

Se identifican como los más importantes productos exportados por Ecuador hacia Bulgaria los siguientes: frutos comestibles, cortezas de agrios o de melones, los cuales muestran la tendencia de crecimiento muy pronunciada, especialmente en los últimos tres años de análisis.
Otras exportaciones ecuatorianas, de menor volumen, hacia el mercado de Bulgaria son: plantas vivas y productos de la floricultura; preparados de legumbres, hortalizas, frutos o de otras partes de plantas; pescados y crustáceos moluscos y otros invertebrados acuáticos, también cacao, entre otros. 


\section{Proyecciones de las exportaciones ecuatorianas hacia Eslovaquia}

\begin{tabular}{|l|c|c|c|c|}
\hline \multirow{2}{*}{ Producto 1 } & \multirow{2}{*}{ Capítulo } & \multicolumn{3}{|c|}{ Proyección (miles de USD) } \\
\cline { 3 - 5 } & $\mathrm{Y} \mathrm{(2015)}$ & $\mathrm{Y} \mathrm{(2016)}$ & $\mathrm{Y}$ (2017) \\
\hline $\begin{array}{l}\text { Plantas vivas y productos } \\
\text { de la floricultura }\end{array}$ & 06 & 4101 & 4852 & 5603 \\
\hline
\end{tabular}

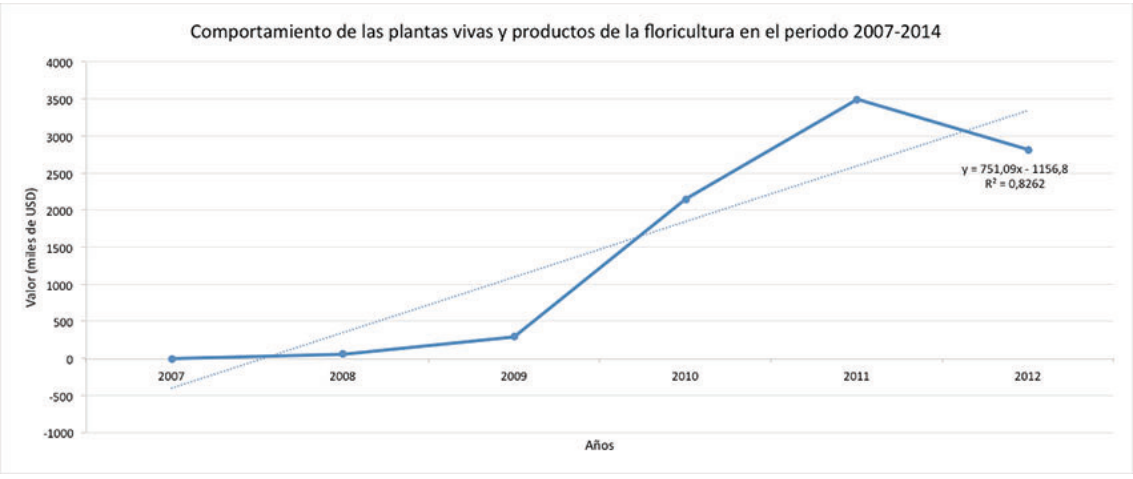

Los productos más importantes de las exportaciones ecuatorianas hacia Eslovaquia son: plantas vivas y productos de la floricultura. En el análisis, originalmente, se observó que el coeficiente de determinación obtenido sin aislar dato alguno fue bajo, por lo que se decidió aislar los dos datos atípicos. Después de aislar los datos de los años 2013 y 2014, el resultado obtenido del coeficiente de determinación permitió realizar una proyección confiable y válida sobre el comportamiento del producto. Se evidencia que en los años 2010, 2011 y 2012 se ex- perimentó un crecimiento mayor de las exportaciones ecuatorianas del producto: plantas vivas y productos de la floricultura.

Otras exportaciones ecuatorianas, de menor volumen, hacia el mercado de Eslovaquia son preparaciones de carne, de pescado o de crustáceos y de moluscos; combustibles minerales, aceites minerales y productos de su destilación; los azúcares y artículos de confitería, como también los productos de origen animal, entre otros. 


\section{Proyecciones de las exportaciones ecuatorianas hacia Hungría}

\begin{tabular}{|l|c|c|c|c|}
\hline \multirow{2}{*}{ Producto 1} & \multirow{2}{*}{ Capítulo } & \multicolumn{3}{|c|}{ Proyección (miles de USD) } \\
\cline { 3 - 5 } & $Y$ (2015) & $Y$ (2016) & $Y$ (2017) \\
\hline $\begin{array}{l}\text { Plantas vivas y productos } \\
\text { de la floricultura }\end{array}$ & 06 & 722 & 826 & 931 \\
\hline
\end{tabular}

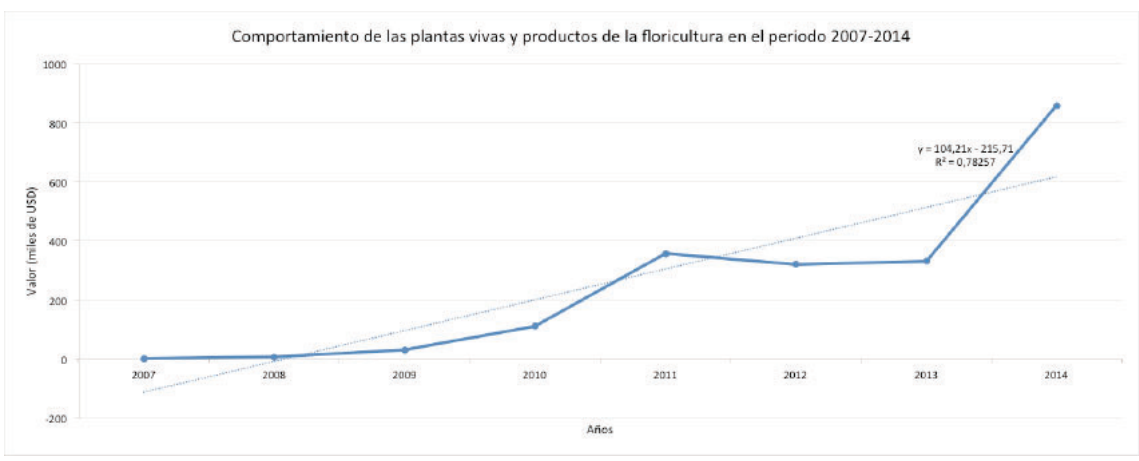

Los productos más importantes de las exportaciones ecuatorianas hacia Hungría son: plantas vivas y productos de la floricultura. Cabe señalar que el resultado obtenido en el análisis del coeficiente de determinación permitió realizar una proyección confiable y válida sobre el comportamiento del producto, por lo que no fue necesario aislar ningún dato. Se evidencia que en los últimos cuatro años las exportaciones ecuatorianas del producto: plantas vivas y productos de la floricultura experimentaron un crecimiento mayor que en años anteriores.
Con relación a los restantes productos de exportación del Ecuador a Hungría podemos anotar que, en cuanto al monto total de exportación, fueron muy insignificantes, por lo que no fue viable realizar la proyección para años posteriores debido a que la mayoría de datos registrados para el periodo 20072014 fueron cero. Solamente podemos mencionar que estos productos fueron las preparaciones de carne, pescado o crustáceos, moluscos; azúcares y artículos de confitería; frutos comestibles, cortezas de agrios o de melones. 


\section{Proyecciones de las exportaciones ecuatorianas hacia Polonia}

\begin{tabular}{|l|c|c|c|c|}
\hline \multirow{2}{*}{ Producto 1 } & Capítulo & \multicolumn{3}{|c|}{ Proyección (miles de USD) } \\
\cline { 3 - 5 } & $\mathrm{Y} \mathrm{(2015)}$ & $\mathrm{Y}$ (2016) & $\mathrm{Y}$ (2017) \\
\hline $\begin{array}{l}\text { Preparaciones alimenticias } \\
\text { diversas }\end{array}$ & 21 & 62877 & 68458 & 74038 \\
\hline
\end{tabular}

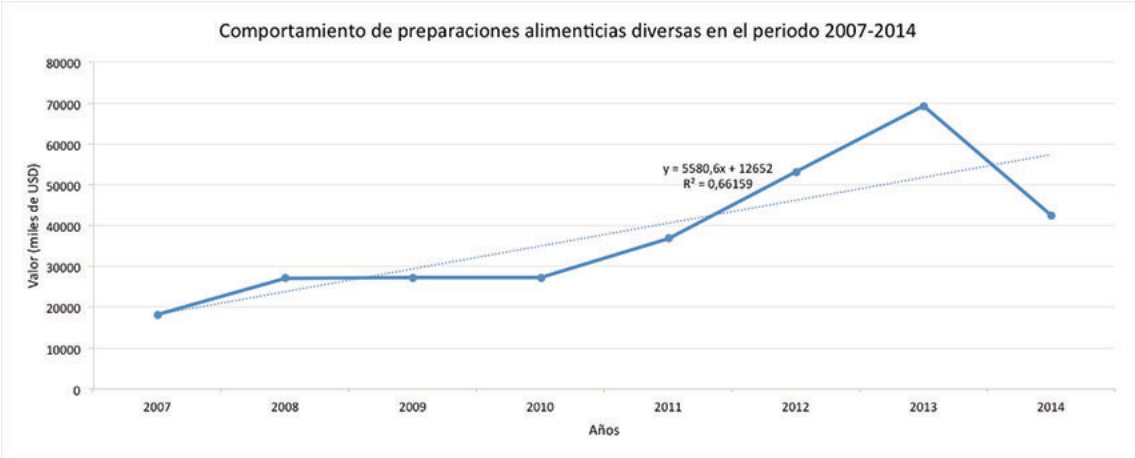

Los productos más significativos de las exportaciones ecuatorianas hacia Polonia son preparaciones alimenticias diversas. El resultado obtenido del coeficiente de determinación permitió realizar una proyección confiable y válida sobre el comportamiento del producto, por lo que no fue necesario aislar ningún dato. Se evidencia que en los últimos cuatro años las exportaciones del producto: preparaciones alimenticias diversas, experimentó un crecimiento mayor que en años anteriores.
Otras exportaciones ecuatorianas, de menor volumen, hacia el mercado de Polonia son frutos comestibles, cortezas de agrios o de melones; tabaco y sucedáneos del tabaco elaborados; la preparación de legumbres, hortalizas, frutos o de otras partes de plantas y, además azúcares y productos de confitería, entre otros. 


\section{Proyecciones de las exportaciones ecuatorianas hacia la República Checa}

\begin{tabular}{|l|c|c|c|c|}
\hline \multirow{2}{*}{$\begin{array}{l}\text { Producto 1 } \\
\begin{array}{l}\text { Preparaciones de carne, } \\
\text { de pescado o de crustáceos } \\
\text { y de moluscos. }\end{array}\end{array}$} & Capítulo & Y (2015) & Y (2016) & Y (2017) \\
\cline { 2 - 5 } & 16 & 2225 & 2537 & 2848 \\
\hline
\end{tabular}

Comportamiento de las preparaciones de carne, de pescado o de crustáceos y de moluscos en el periodo 2007-2014

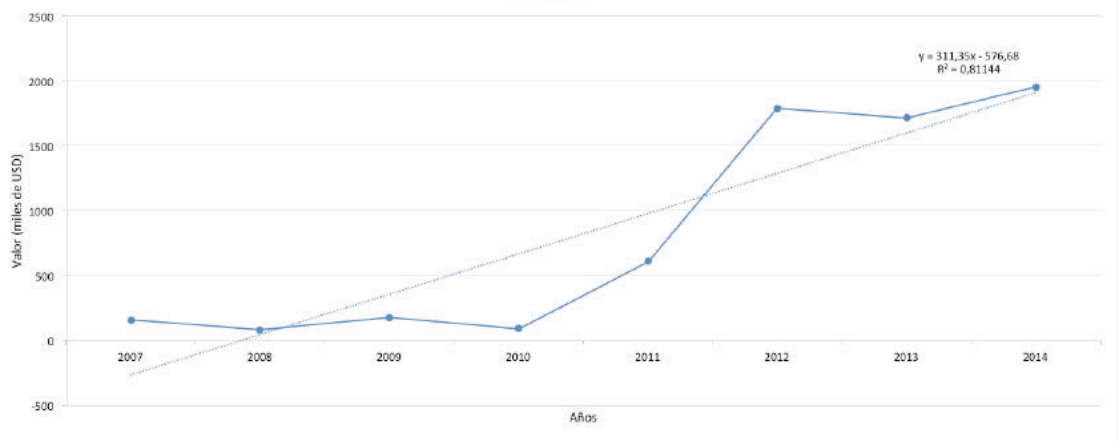

Los productos más representatipescado o de crustáceos y de moluscos, vos de las exportaciones ecuatorianas hacia la República Checa son: preparaciones de carne, de pescado o de crustáceos y de moluscos. Podemos colegir que el resultado obtenido del coeficiente de determinación permitió realizar una proyección confiable y válida sobre el comportamiento del producto, por lo que no fue necesario aislar ningún dato. Se evidencia que en los últimos cuatro años el producto: preparaciones de carne, de

experimentó un crecimiento mayor que en años anteriores

Otras exportaciones ecuatorianas, de menor volumen, hacia el mercado de Republica Checa son plantas vivas y productos de la floricultura; madera, carbón vegetal y manufacturas de madera y, en menor grado, el tabaco, tabaco elaborado y las preparaciones alimenticias diversas. 


\section{Proyecciones de las exportaciones ecuatorianas hacia Rumanía}

\begin{tabular}{|l|c|c|c|c|}
\hline \multirow{2}{*}{ Producto 1 } & Capítulo & \multicolumn{3}{|c|}{ Proyección (miles de USD) } \\
\cline { 3 - 5 } & $\mathrm{Y} \mathrm{(2015)}$ & $\mathrm{Y}$ (2016) & $\mathrm{Y}$ (2017) \\
\hline $\begin{array}{l}\text { Preparaciones de carne, } \\
\text { de pescado 0 de crustáceos } \\
\text { y de moluscos. }\end{array}$ & 16 & 1794 & 2058 & 2322 \\
\hline
\end{tabular}

Comportamiento de las preparaciones de carne, de pescado o de crustáceos y de moluscos en el periodo 2007-2014

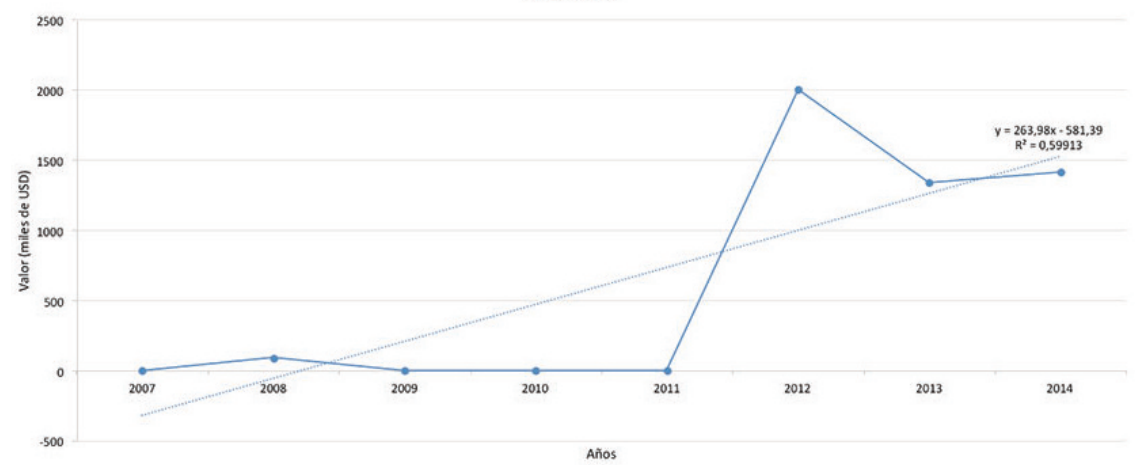

Los productos más importantes de las exportaciones ecuatorianas hacia Rumania son preparaciones de carne, de pescado o de crustáceos y de moluscos. El resultado obtenido del coeficiente de determinación permitió realizar una proyección confiable y válida sobre el comportamiento del producto, por lo que no fue necesario aislar ningún dato. Asimismo, se observa que en los últimos tres años, el producto preparaciones de carne, de pescado o de crustáceos y de moluscos, experimentó mayor crecimiento que en años anteriores.

Otras exportaciones ecuatorianas, de menor volumen, hacia el mercado de Rumanía son pescados y crustáceos, moluscos y otros invertebrados acuáticos; frutos comestibles, cortezas de agrios o de melones; plantas vivas y productos de la floricultura; aceites esenciales, preparaciones de perfumería y de tocador, entre otros. 


\section{CONCLUSIONES}

- La producción exportable del Ecuador, en su mayor porcentaje, está constituida por los productos del sector primario, es decir de "commodities" como el petróleo crudo, banano, café y elaborados, camarón, cacao y elaborados, atún y pescado; situación que conlleva una vulnerabilidad implícita, al estar expuestos a la volatilidad de los precios de estos bienes dentro del mercado mundial.

- El sector camaronero ha tenido un crecimiento importante en los últimos años gracias al precio internacional y a la disminución de producción de países competidores. En el 2014 el monto total de exportaciones de camarón estuvo muy próximo al valor del mayor bien de exportación no petrolero, el banano.

- Las exportaciones petroleras en el Ecuador representaron más de la mitad de las exportaciones totales en los años de análisis. El 2009 y el 2014 fueron años atípicos en cuanto la dependencia en términos porcentuales fue menor; en el primer año las exportaciones disminuyeron por la crisis mundial y en el segundo debido al precio en el mercado internacional.

- En términos de intercambio comercial se considera que las economías de Europa del Este con la ecuatoriana son complementarias en cuanto Ecuador exporta bienes primarios; y Bulgaria,
Eslovaquia, Hungría, Polonia, República Checa y Rumanía exportan maquinaria que puede ser utilizada para procesar los "commodities".

- Se resalta que los productos ecuatorianos exportados hacia los seis países de Europa del Este corresponden casi su totalidad a productos del sector primario y en algunos casos estos han experimentado algún tipo de procesamiento adicional.

- Ecuador tiene saldo positivo y bien pronunciado en el comercio exterior con Polonia, y se quiere anotar que las relaciones comerciales entre estos dos países son mucho más dinámicas que con el resto de los países analizados en esta investigación.

- Ecuador tiene saldo positivo en el comercio exterior con Bulgaria; sin embargo, las relaciones comerciales entre estos dos países son de poca importancia si se refiere al volumen del comercio exterior.

- Ecuador tiene saldo negativo en el comercio exterior con Eslovaquia, Republica Checa, Hungría y Rumanía y los volúmenes del comercio exterior entre Ecuador y estos cuatro países de Europa del Este son realmente pequeños, un poco mayores con Republica Checa y Rumanía, y realmente insignificantes con Eslovaquia y Hungría. 


\section{PERSPECTIVAS COMERCIALES DE ECUADOR VERSUS PAÍSES DE EUROPA DEL ESTE}

- En cuanto a las perspectivas a corto plazo de los principales grupos de productos ecuatorianos exportados hacia Bulgaria se prevé un comportamiento favorable para el Ecuador en los siguientes bienes: frutos comestibles, cortezas de agrios o de melones; plantas vivas y productos de la floricultura; preparados de legumbres, hortalizas, frutos o de otras partes de plantas; y en menor volumen pescados y crustáceos moluscos y otros invertebrados acuáticos, como también cacao, entre otros.

- Los productos ecuatorianos de mayor demanda en Eslovaquia son: plantas vivas y productos de la floricultura; preparaciones de carne, de pescado o de crustáceos y de moluscos; otros productos, y de menor volumen combustibles minerales, aceites minerales y productos de su destilación, los azúcares y artículos de confitería, como también los productos de origen animal, entre otros.

- Las proyecciones de las exportaciones ecuatorianas a Hungría son positivas ya que denotan un crecimiento en los bienes plantas vivas y productos de la floricultura; otros productos. En el caso de las preparaciones de carne, de pescado o de crustáceos, de moluscos; los azúcares y artículos de confitería; los frutos comestibles, cortezas de agrios o de melones, entre otros, presenta una relación poco definida entre el tiempo y la demanda.

- Las perspectivas a corto plazo con PoIonia son positivas en los siguientes productos: preparaciones alimenticias diversas; frutos comestibles; cortezas de agrios o de melones; otros productos; tabaco y sucedáneos del tabaco elaborados; la preparación de legumbres, hortalizas, frutos o de otras partes de plantas; sin embargo, no existe un patrón de demanda con tendencia para los azúcares y productos de confitería, entre otros.

- Los productos ecuatorianos de mayor demanda en República Checa son: preparaciones de carne, de pescado o de crustáceos y de moluscos; plantas vivas y productos de la floricultura; otros productos; madera, carbón vegetal y manufacturas de madera; y en menor grado el tabaco, tabaco elaborado y preparaciones alimenticias diversas.

- Las tendencias de las exportaciones del Ecuador hacia Rumanía son optimistas en los productos: plantas vivas y productos de la floricultura; pescados y crustáceos, moluscos y otros invertebrados acuáticos; las preparaciones de 
carne, de pescado o de crustáceos y de moluscos; frutos comestibles, cortezas de agrios o de melones; y otros productos. No obstante, la tendencia poco definida del bien aceites esenciales y resinoides, preparaciones de perfumería y de tocador no permitió realizar una proyección confiable.

- Ecuador exporta sus productos a un universo de cerca de 190 países, de los cuales 28 forman parte de la Unión Europea que se ha convertido en el segundo socio más importante para el Ecuador después de los Estados Unidos.

- Cabe señalar que el Ecuador mantiene relaciones comerciales con cada uno de los países miembros por lo que el acuerdo comercial con la Unión Europea favorecería al país en cuanto se eliminan parcial o totalmente los aranceles en ciertos productos y permitiría que los productos ecuatorianos sean más competitivos en el mercado europeo.
- El mercado europeo normalmente ha sido muy exigente; sin embargo, muchos países desean tener a la Unión Europea como socio comercial ya que la introducción de los productos a este bloque comunitario abre las puertas hacia veintiocho países miembros. En tal sentido, el beneficio radica en que el país exportador simplemente realiza el procedimiento común establecido por la Unión Europea para la exportación hacia cualquier país integrante del bloque.

- La supresión de restricciones arancelarias negociadas sería beneficioso para el país en cuanto se eliminan barreras comerciales que pueden ser aprovechadas satisfactoriamente, ya que no se pagaría aranceles tan elevados; por ejemplo, el 38\% en la partida del chocolate y demás preparaciones alimenticias que contengan cacao; o se beneficiaría de reducciones arancelarias que incluso podrían llegar a cero en ciertas partidas.

\section{RECOMENDACIONES}

- El Ecuador debe diversificar su oferta exportable ya que el $91 \%$ de las exportaciones totales corresponden a seis productos que son el petróleo, el banano y el plátano, café y elaborados, camarón, cacao y elaborados, y atún y pescado. Entre los bienes que son apreciados en los países del Este Europeo están bolsos, sombreros, quinua, artesanías, productos textiles, entre otros.

- Exportar los productos primarios con valor agregado, es decir, con un procesamiento adicional ya que de esta manera se genera inversión y empleos en el país y se obtienen mayores ga- 
nancias que al exportar el producto en estado natural.

- Los empresarios ecuatorianos deben estar atentos al comportamiento y tendencias de los productos no petroleros tradicionales y no tradicionales en el mercado internacional para enfocarse en la producción de aquellos bienes con mayor precio y demanda a nivel mundial.

- El comercio exterior del Ecuador con varios de los países de la Unión Europea es casi nulo, por lo que consideramos que se puede aprovechar esta situación para promover y consolidar vínculos comerciales con cada uno de los miembros de este mercado común y así diversificar sus socios comerciales, maximizar beneficios y evitar la dependencia en uno o en pocos países.

- El Acuerdo Comercial -no vigente aún- firmado por el Ecuador con la Unión Europea en julio de 2014, es una oportunidad y un reto; a su vez, el país se ve obligado a ser más competitivo si desea consolidarse en el mercado europeo. Consideramos que se debe trabajar eficientemente en mejorar la calidad de los productos ya que la dolarización en el Ecuador es vista como una barrera que no permite igualar en precios a los países vecinos como Colombia y Perú.

- Se debería gestionar acuerdos comer- ciales bilaterales complementarios entre el Ecuador y cada uno de los seis países de Europa del Este ya que se podrían obtener mayores beneficios que los negociados en el Acuerdo Comercial con la Unión Europea.

- Tomando en cuenta que la Unión Europea es el mayor socio no petrolero del Ecuador, se debe enfocar esfuerzos en mantener buenas relaciones con el bloque europeo y fomentar el comercio exterior a través de la promoción planificada de productos ecuatorianos en ferias, rondas de negocios, entre otros.

- Con el fin de promover las exportaciones, el gobierno ecuatoriano debería encargarse de facilitar capacitaciones, crédito y financiamiento para los pequeños empresarios ecuatorianos que buscan exportar sus productos hacia la Unión Europea; puesto que no cuentan con la tecnología, recursos humanos y financieros suficientes.

- De igual manera, el cambio de la matriz productiva propuesta por el gobierno ecuatoriano actual se ha conver- tido en uno de los motores para lograr el desarrollo del país por lo que se debe fomentar la exportación de productos que cuenten con un mayor procesamiento y valor agregado. 


\section{BIBLIOGRAFÍA}

Bravo Chuquillanque, E. (2009). Documentos utilizados en el comercio exterior. Buenos Aires: El Cid Editor | apuntes.

Carrera Galicia, O., Nicolás Huerta, S., \& Pérez Torres, M. (Diciembre de 2009). Tesis IPN México. Recuperado el 17 de marzo de 2015, de Tesis IPN México: http://tesis.ipn.mx/bitstream/handle/123456789/6622/CP2009\%20 C343o.pdf?sequence $=1$

Coral, M. L. (September de 2013). Universidad Andina Simón Bolívar. Obtenido de Universidad Andina Simón Bolívar: http:// www.uasb.edu.ec/UserFiles/372/File/pdfs/N OTICIASYSUCESOS/2013/Ecuador\%20UE\%20 logicas\%20negociacion\%20inconclusa\%20 M\%20LEVI\%20FES\%20Ecuador\%20vdef\%20। X13.pdf

European Commission. (13 de Novemeber de 2015). Trade Export Helpdesk. Obtenido de Trade Export Helpdesk: http://exporthelp.europa.eu/thdapp/display.htm?page=cd\%2fcd_SistemaDePreferenciasGeneralizadas.html\&docType=main\&l anguageld=es

González Lanzarote, R. (2013). Manual Negociación y compraventa internacional. Madrid: Editorial CEP.

González López, I., Martínez Senra, A. I., Otero Neira, M. C., \& González Vasquéz , E. (2014). Gestión del Comercio Exterior de la empresa. Madrid: Esic Editorial.

Lafuente, F. (2012). Aspectos de comercio exterior. Madrid: B - EUMED.
Lluc López, V. (2010). La política exterior y de seguridad japonesa. Barcelona: Editorial UOC.

Martín Martín, M., \& Martínez Gormaz, R. (2014). Manual Práctico de Comercio Exterior. Madrid, España: FC Editorial.

Ministerio de Comercio Exterior. (31 de December de 2014). Comercio Exterior. Obtenido de Comercio Exterior: http://www.comercioexterior.gob.ec/wp-content/uploads/ downloads/2015/04/CARTILLA-UNION-EUROPEA-1.pdf

Parlamento y Consejo Europeo. (2012 de October de 2012). Trade Export Helpdesk. Obtenido de Trade Export Helpdesk: http://eur-lex.europa.eu/LexUriServ/LexUriServ.do?uri=OJ:L:2012:303:FULL:ES:PDF

Secretaría de Estado de Comercio. (s.f.). Secretaría de Estado de Comercio. Obtenido de Secretaría de Estado de Comercio: http://www.comercio.gob.es/es-es/comercio-exterior/politica-comercial/medidasarancelarias/paginas/sistema-de-preferencia s-generalizadas-spg.aspx

Subdirección de Política Arancelaria y de Instrumentos de Defensa Comercial. (31 de December de 2012). Revistas ICE. Obtenido de Revistas ICE: http://www. revistasice.com/CachePDF/BICE_3034_3-16_2332 EF5E0C216AC61C28A3642D284D81.pdf

Unión Europea. (18 de August de 2015). Delegación de la Unión Europea para Ecuador. Obtenido de Delegación de la 
Unión Europea para Ecuador: http://ec.europa.eu/trade/policy/countries-and-regions/development/generalised-scheme-ofpreferences/index_en.htm

Unión Europea. (s.f.). Unión Europea Acción Exterior. Obtenido de Unión Europea Acción Exterior: http://www.eeas.europa.eu/ ecuador/index_es.htm 